\title{
WAVE PROPAGATION SCATTERING DUE TO DEFECTS ON THIN COMPOSITE PLATES
}

\author{
Z. M. Hafizi ${ }^{1,2}$, J. Epaarachchi ${ }^{1}$ and K. T. Lau ${ }^{1}$ \\ ${ }^{1}$ Centre of Excellence in Engineered Fiber Composites, University of Southern \\ Queensland, Toowoomba QLD 4350, Australia \\ ${ }^{2}$ Faculty of Mechanical Engineering, University Malaysia Pahang, \\ 26600 Pekan, Pahang, Malaysia \\ MohdHafiziBin.Zohari@usq.edu.au
}

\begin{abstract}
Engineering structures which are based on laminated composites have a high probability of unexpected damage developing during service. The damaged formations must be monitored from the beginning before they head towards structural failure which could result in substantial damage. This leads to the necessity of a structural health monitoring (SHM) system to be installed during the construction of laminated composite structures. However, an understanding of damage area detection and damage characteristics is essential before a SHM system can be integrated into the structures. This article presents the effects of wave propagation through an existing area of damage on composite plates. Theoretically, a propagating wave that starts from any source will vary when crossing an area with damage. This study shows that high frequency wave propagation $(\mathrm{kHz}$ range) reacts differently when passing through the damaged area, compared with low frequency wave propagation. The results of the study will lead to an effective damage detection method, utilizing the available vibration source, especially for the condition monitoring of thin laminated composite structures.
\end{abstract}

Keywords: SHM, wave propagation, wavelet analysis, Gl/epoxy composites.

\section{INTRODUCTION}

Composite material is one of the catalysts for the growth of modern structures, and especially the development of smart structures. For instance, the high ratio of material strength compared to its weight means that it has become one of the main choices in aircraft construction. However, the structure of the composite material is exposed to the risk of the formation and propagation of internal damage, which is hard to predict. Failure of the structure can start from various causes, either during the manufacturing process (e.g. voids) or when the structure is being used (e.g. impact or fatigue). This is a strong reason why an effective SHM system needs to be installed in every composite structure. One of the concepts in SHM, so-called wave-propagation-based SHM, is becoming popular recently. The idea is based on the propagation of acoustic waves. In general, this method is usually referred to as guided waves, ultrasonic guided waves, or Lamb waves. (Croxford, Wilcox, Drinkwater, \& Konstantinidis, 2007) have claimed that guided acoustic waves may be the only detection method that combines an acceptable level of damage detection sensitivity with a significant propagation range. Moreover, waveform analysis of the guided waves can provide more detailed information on the location and nature of smaller defects (Mal, Ricci, Banerjee, \& Shih, 2005). A thorough literature study has been done by (Diamanti \& Soutis, 2010) on the 
use of Lamb waves in aircraft composite structure and they concluded that this technique can lead to an active SHM for laminated composite structures, utilizing piezoelectric wafers embedded into layered composite structures. Composite materials display a wide variety of failure mechanisms as a result of their complex structure and manufacturing processes, which include fiber failure, matrix cracking, buckling and delamination (Ibrahim, Sapuan, \& Faieza, 2012; Orifici, Herszberg, \& Thomson, 2008; Umar, Zainudin, \& Sapuan, 2012). Damage can develop and propagate very slowly from inside the composite layers (e.g. matrix cracks, delamination and matrix-fiber debonding) (Adebisi, Maleque, \& Rahman, 2011; Shan, Ghazali, \& Idris, 2013). As a result, it will affect the material properties of the composites, such as their strength and stiffness. The formation of damage such as matrix cracking can sometimes be seen with the naked eye; however, damage such as delamination is a silent killer, in that it is almost impossible to detect from the surface of the structure. There are various methods, highlighted by the researchers, to identify the damage in composite structures, and particularly for thin laminated composite plates such as the fiber Bragg gratings, ultrasonic, acousto-ultrasonic, x-ray imaging, and acoustic emission(AE) methods (Bhaskar \& Sharief, 2012; Kahandawa, Hafizi, Epaarachchi, \& Lau, 2012; Lam, Lau, Ling, Su, \& Tam, 2009; Muravin, Muravin, \& Lezvinsky, 2010; Popovics, 2009). However, the passive fault detection system was chosen as the focus in this study, as it can be used online, is more practical, requires less equipment and is a relatively cheap system. One of the main challenges for a passive system is to create a classifying technique which can evaluate the condition of the examined structures. In other words, passive monitoring must be combined with good signal analysis in order to produce a robust and reliable system. AE techniques may suit the need. Although AE usage is highly established for metallic materials, there is a huge challenge in detecting good AE signals that can be correlated with any damage formation and propagation, especially where composite materials are involved.

This present study highlights a different approach/concept which may be a more practical alternative in real application. The idea is to manipulate the available vibration source in order to identify the existence of damage in thin composite plates. This concept can also be considered as a form of passive monitoring. We consider a composite structure that is constantly exposed to constant vibration; in any frequency range, this will produce wave propagation in the structure. For thin plates, this wave propagation is called the Lamb waves. When the wave propagates through areas with damage, such as matrix cracking or delamination, this wave will change its form and some characteristics, as it is affected by the existence of the damaged area. This article will reveal the results of several experiments that have been carried out on a thin composite sample in which a small hole has been made to indicate the presence of the damaged area.

\section{EXPERIMENTATION}

$265 \mathrm{~mm} \times 97 \mathrm{~mm} \times 4.4 \mathrm{~mm}$ of Gl/epoxy resin laminates with a stacking sequence of $\left[0^{*}\right]_{\mathrm{B}}$ were fabricated by a hand lay-up method. A hole was drilled in the middle of the sample as indicated in Figure 1. Two case studies were done, with the aim of understanding the effect of high frequency and low frequency wave propagation passing through the damaged area. 


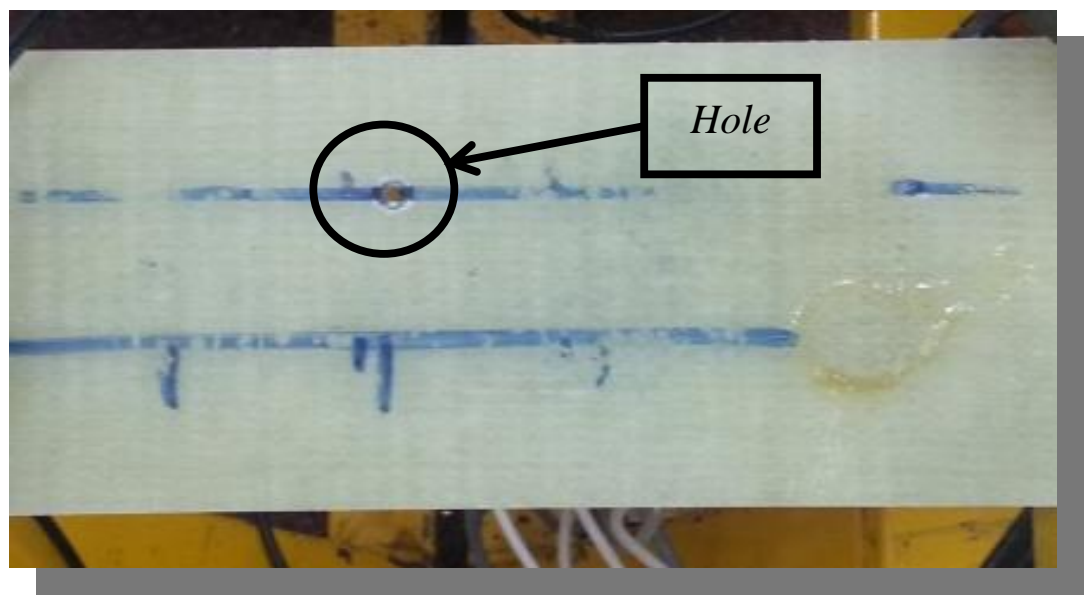

Figure 1. Gl/epoxy resin laminates for the experiments.

\section{High Frequency Case}

Figure 2 shows the experimental setup. Two piezoelectric sensors (numbers' 1 ' and '2', as shown in Figure 2) were coupled to the surface of the plate. The sensors were individually connected to two PAC AE Node Systems (data acquisition from Physical Acoustic Corporation) for waveform acquisition and were synchronized with the help of $A E$ Win software. The sampling rate for acquisition was set to $1 \mathrm{Mega}$ sample per second and the threshold was set to $45 \mathrm{~dB}$.

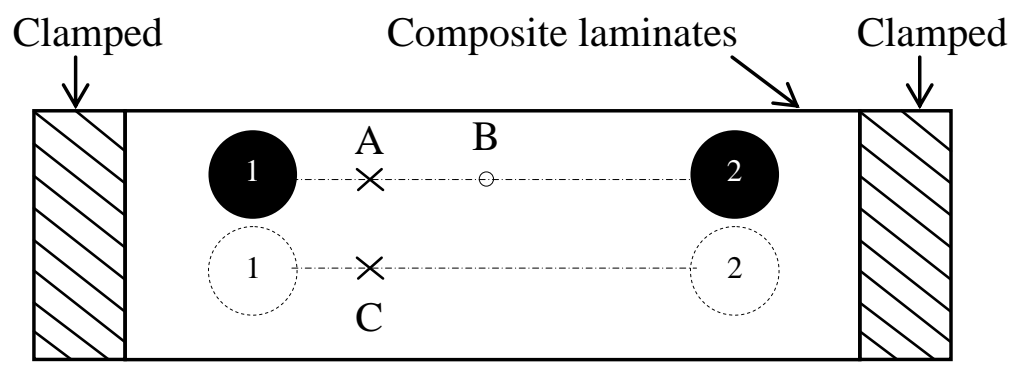

Figure 2. Setup for high frequency source' test.

Point B indicates the hole's location. A pencil lead break (PLB) test was done at point A. A PLB test was chosen as it can excite high frequency wave propagation, at approximately $30 \mathrm{kHz}$. The signal propagation due to the lead breaking will be acquired by both piezoelectric sensors. For this case, sensor ' 2 ' captured the signal which was propagating across the artificially damaged area (hole). Finally, for comparison, the lead breaking was also done at point $\mathrm{C}$, as this area has no damage in between the sensors.

\section{Low Frequency Case}

The test arrangement was as shown in Figure 3. Both piezoelectric sensors were connected directly to a digital storage oscilloscope and the sampling rate was set to 100 $\mathrm{kHz}$. An impact with a hammer at point $\mathrm{F}$ was the method used to excite the low frequency wave propagation on the thin plates. The wave propagated and traveled 
across point B and was then captured by sensor ' 1 '. At the same time, sensor ' 2 'also detected this signal, but it was not propagating through any damaged area before reaching the sensor. The impacts were repeated at points $\mathrm{E}$ and $\mathrm{F}$, where no wave propagation was expected to cross the damaged area.

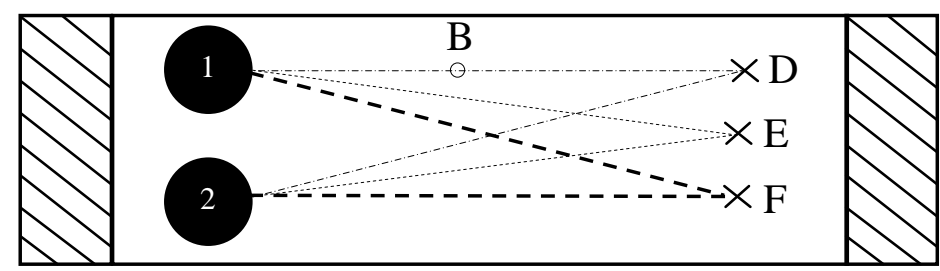

Figure 3. Arrangement for low frequency source test.

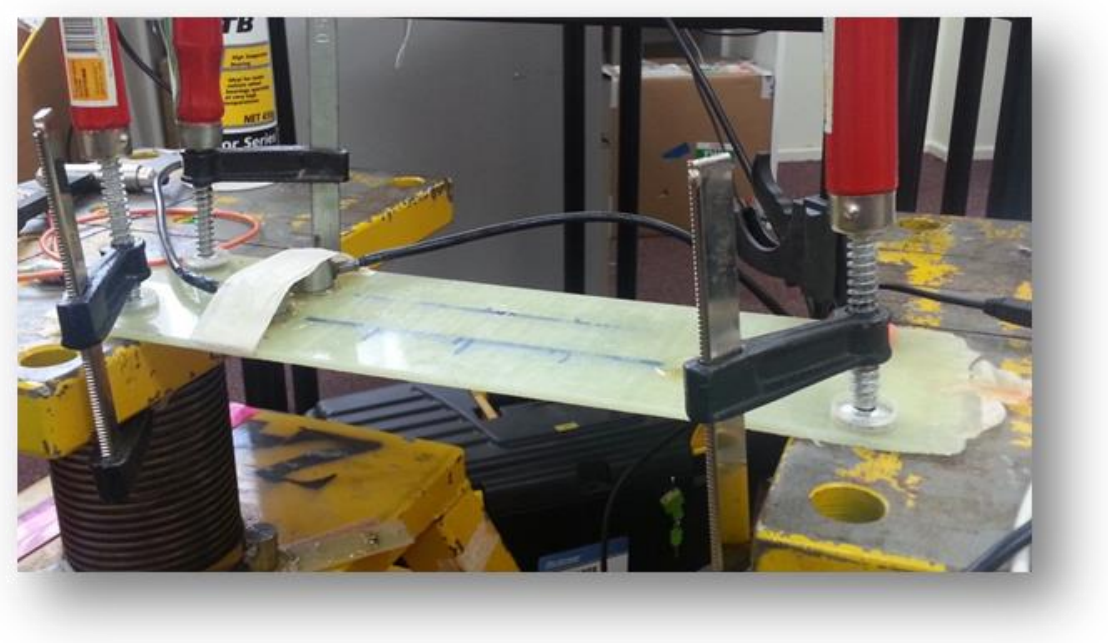

Figure 4. Specimen prepared before the low frequency impact by hammer.

\section{RESULTS AND DISCUSSION}

When a Lamb wave propagates past the damaged area, it will experience a wave scattering. The wave scattering effect due to defects in composite materials has been discussed theoretically by a number of researchers. The wave scattering varies depending on the propagating wave frequency range. Based on several experiments that have been done, the propagation of a high frequency wave experienced a very clear wave scattering, compared with the wave propagation of the low frequency range.

\section{High Frequency Case}

Figures 5 and 6 show the waveform and its respective fast Fourier transform (FFT) of Lamb wave signals due to the PLB at points A and C. It is difficult to evaluate the difference between the signals obtained from the two sensors, except for an obvious reduction in the signal amplitude and signal energy, which is caused by the effects of attenuation. The same is true when looking at the results of comparisons of their FFT analysis. Therefore, further analysis is needed to see more clearly the effects of this wave scattering. However, the two major modes of wave propagation can still be 
observed, and they are always associated with Lamb wave propagation: the flexural and extensional modes.

(a)

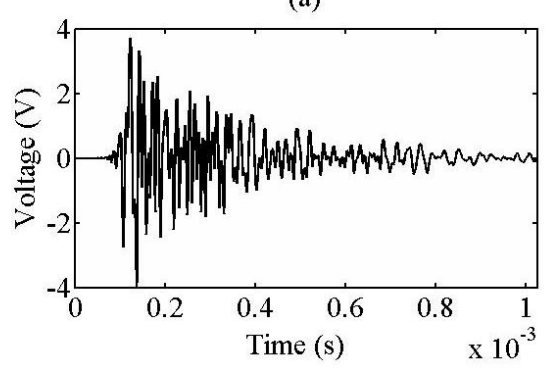

(c)

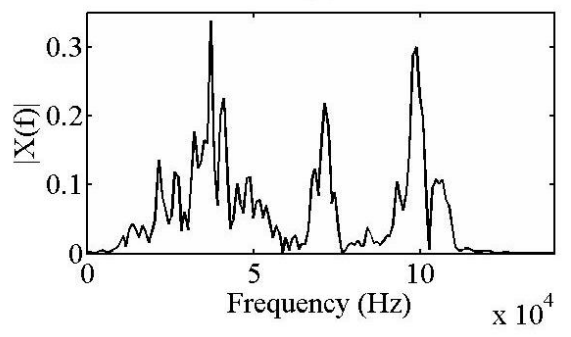

(b)

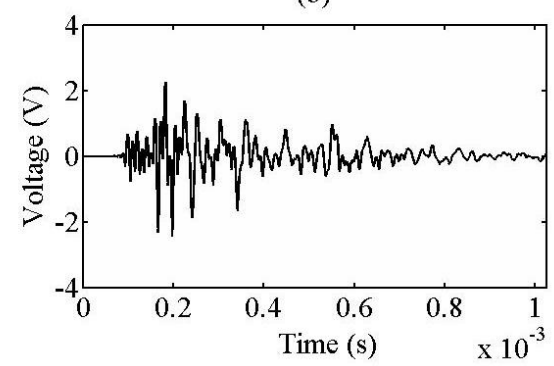

(d)

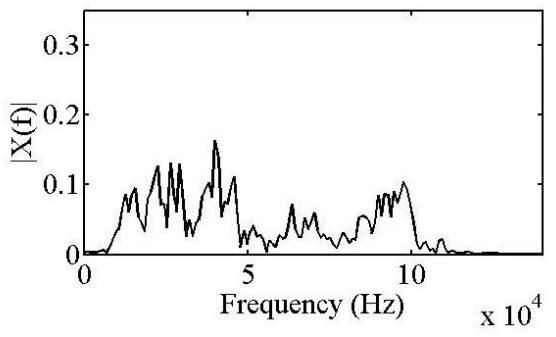

Figure 5. Response due to PLB at point A: (a) and (c) are from sensor ' 1 ', while (b) and (d) are from sensor ' 2 '.

(a)

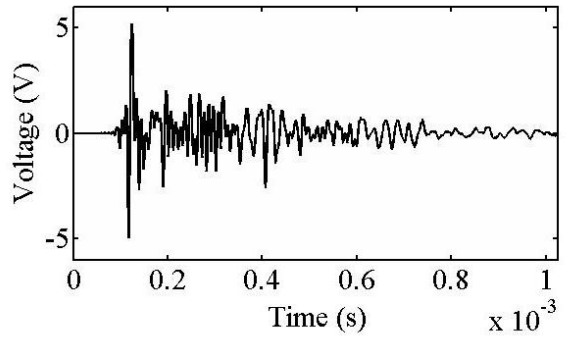

(c)

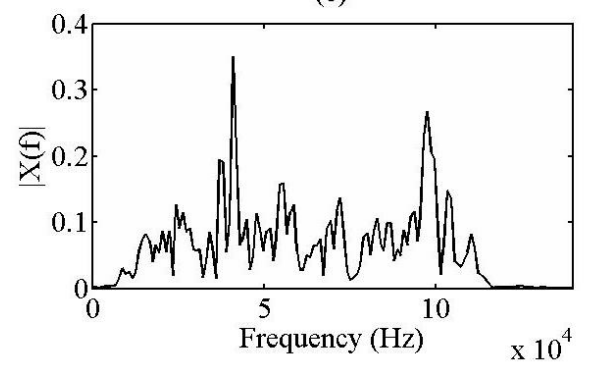

(b)

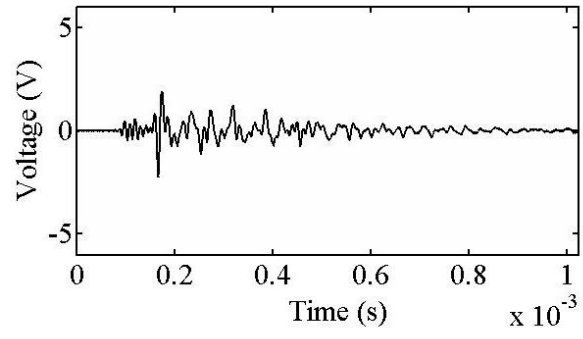

(d)

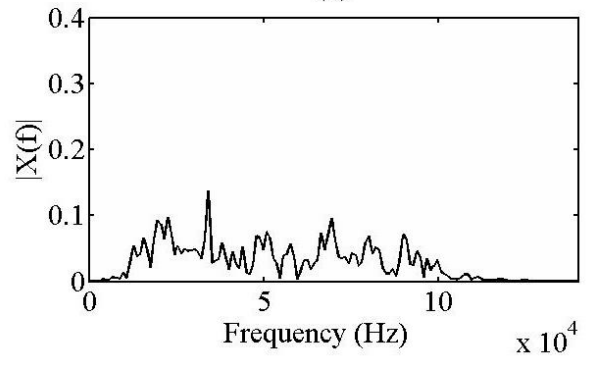

Figure 6.Response due to PLB at point D: (a) and (c) are from sensor ' 1 ', while (b) and (d) are from sensor ' 2 '.

Meanwhile Figure 7 shows the result after the continuous wavelet transform (CWT) is performed on the signals. The CWT, one of the time-frequency analyses, can provide extra information from any given time domain signal (Hamstad, 
O‘GALLAGHER, \& Gary, 2002; Jingpin, Bin, \& Cunfu, 2008; Zohari, Epaarachchi, $\&$ Lau, 2013). The CWT of a function, as defined by (Chui, 1992), can be expressed as

$$
W T_{f}(s, \tau)=\frac{1}{\sqrt{s}} \int_{-\infty}^{\infty} f(t) \psi^{*}\left(\frac{t-\tau}{s}\right) d t
$$

where $s>0$ and the superscript $*$ indicates the complex conjugate. The term $\psi(t)$ is the basic wavelet. The parameter $s$ in Equation 1 stands for the scale of the basic wavelet and is related to the signal frequency. Meanwhile, the parameter $\tau$ stands for the shift or position of the basic wavelet and can be related to the time of the signal. Plotting the wavelet transform magnitude on the $s-\tau$ axis gives the time-frequency view of a signal.

(a)

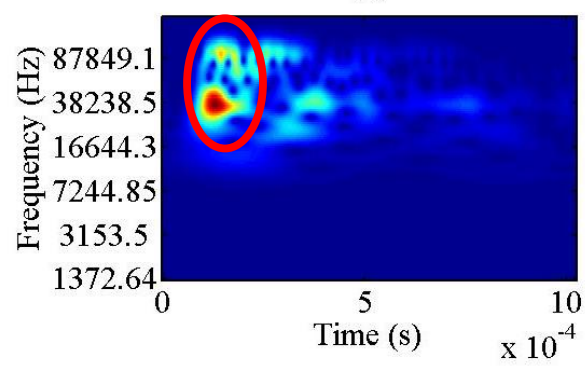

(c)

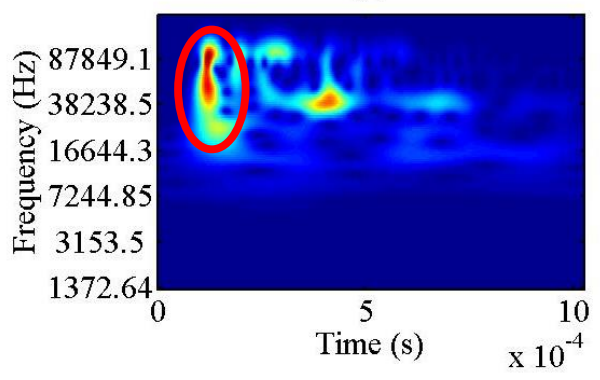

(b)

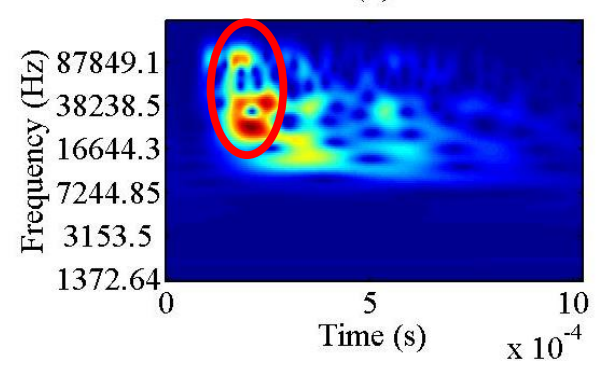

(d)

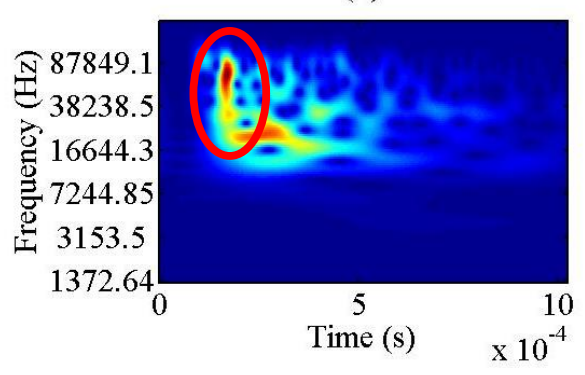

Figure 7. Wavelet analysis of the (a) signal from sensor ' 1 ' due to PLB at A; (b) signal from sensor ' 2 ' due to PLB at A; (c) signal from sensor ' 1 ' due to PLB at C; and (d) signal from sensor ' 2 ' due to PLB at C.

There are many basic wavelets available and the appropriate choice will give a better result. In this study, a Morlet wavelet, which is identical to the Gabor wavelet (Simonovski \& Boltežar, 2003) and has a similar shape to an impulse (Lin, 2001) was used. It can be defined as (Lin, 2001; Simonovski \& Boltežar, 2003)

$$
\psi(t)=\left(e^{-i \omega_{0} t}-e^{-\omega^{2} / 2}\right) e^{-t^{2} / 2}
$$

The scale $s$ can be related with the frequency by this relation:

$$
\omega=\eta / s
$$


where the coefficient $\eta$ can be written as the wavelet center frequency, and $\omega_{0}$ depends on the sampling frequency and the selected minimum scale, as explained by (Simonovski \& Boltežar, 2003). Now we can clearly observe the effect of changes in wave propagation which are caused by the presence of the damaged area. The circles in Figure $7(a, b)$ indicate the changes of the signal waveform in terms of time-frequency analysis due to the existence of the artificial damage. Meanwhile, the results in Figure 7 (c, d) show no significant variation.

For high-frequency wave propagation $(\mathrm{kHz})$, the whole wave will traverse the existing artificial damage area (hole). This is because the wavelength is very small compared to the size of the hole. As a consequence, this leads to the overall impression of the waves undergoing a scattering effect as shown in Figure 7. However, this outcome should not be confused with the wave dispersion and attenuation effect that always occurs when a Lamb wave propagates in a thin plate.

(a) Impact at point $\mathrm{D}$

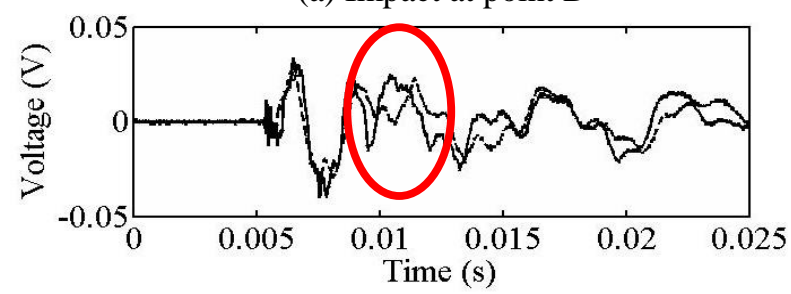

(b)Impact at point $\mathrm{E}$

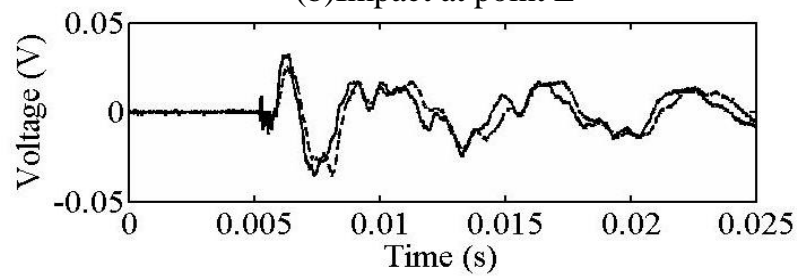

(c) Impact at point $\mathrm{F}$

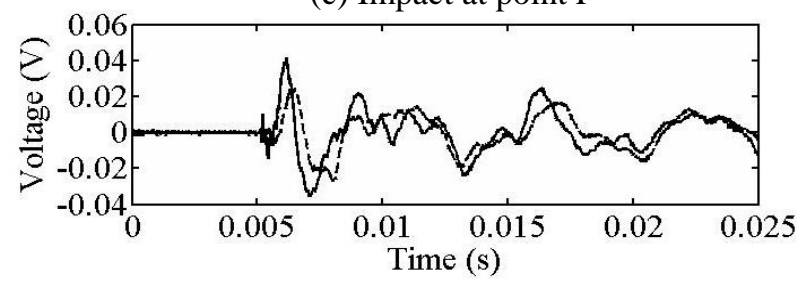

Figure 8.Effect of the low frequency wave traveling across the perforated region (indicated by red circle). Two lines in each figure indicate the two waveforms captured

by the two different sensors (sensor ' 1 ' and sensor ' 2 ').

\section{Low Frequency Case}

In the meantime, for low-frequency wave propagation, the wave packet did not entirely traverse the hole at point B. Part of the propagated wave seems to change a little compared with the wave which propagated without passing the perforated region. After a few tests, it can be observed that 80 to $90 \%$ of the low frequency wave which travels past the artificial damage area will show the changes described in the result in Figure 8.Figure 8 (a) shows that, if the hammer impact is done at point D (see Figure 3), there is a significant difference between the waveforms captured by sensor ' 1 ' and sensor ' 2 ', 
although the waveform actually came from the same source. This situation did not occur if the impact was at another location (E and F). This is because none of the source will propagate across point $\mathrm{B}$ (the hole).

\section{CONCLUSION}

This study has successfully reported on the effects of wave propagation when traversinga defective area. In the case of a real composite structure, propagation may originate from various sources such as engine vibration and rotation of ball-bearings. This investigation is still in the early stages but is already very useful in developing an effective monitoring system for composite structures.

\section{ACKNOWLEDGEMENT}

The authors would like to thank the Faculty of Engineering and Surveying and the Centre of Excellence in Engineered Fibre Composites, University of Southern Queensland, for providing laboratory facilities and financial support. They would also like to thank the Universiti Malaysia Pahang together with the Ministry of Higher Education, Malaysia for scholarship support.

\section{REFERENCES}

Adebisi, A. A., Maleque, M. A., \& Rahman, M. M. (2011). Metal matrix composite brake rotor: Historical development and product life cycle analysis. International Journal of Automotive and Mechanical Engineering, 4, 471-480.

Bhaskar, H. B., \& Sharief, A. (2012). Effect of solutionizing on dry sliding wear of al2024-beryl metal matrix composite. Journal of Mechanical Engineering and Sciences, 3, 281-290.

Chui, C. K. (1992). An introduction to wavelets (Vol. 1): Academic press.

Croxford, A., Wilcox, P., Drinkwater, B., \& Konstantinidis, G. (2007). Strategies for guided-wave structural health monitoring. Proceedings of the Royal Society A: Mathematical, Physical and Engineering Science, 463(2087), 2961-2981.

Diamanti, K., \& Soutis, C. (2010). Structural health monitoring techniques for aircraft composite structures. Progress in Aerospace Sciences, 46(8), 342-352.

Hamstad, M., O‘GALLAGHER, A., \& Gary, J. (2002). A wavelet transform applied to acoustic emission signals: Part 2: Source location. Journal of Acoustic Emission, 20, 62-82.

Ibrahim, M. S., Sapuan, S. M., \& Faieza, A. A. (2012). Mechanical and thermal properties of composites from unsaturated polyester filled with oil palm ash. Journal of Mechanical Engineering and Sciences, 2, 133-147.

Jingpin, J., Bin, W., \& Cunfu, H. (2008). Acoustic emission source location methods using mode and frequency analysis. Structural Control and Health Monitoring, $15(4), 642-651$.

Kahandawa, G. C., Hafizi, Z. M., Epaarachchi, J., \& Lau, K. T. (2012, Dec.9-12). Detecting delamination in a composite structure using an embedded fbg - ae hybrid system. Paper presented at the 7th Australasian Congress on Applied Mechanics (ACAM 7), Adelaide, Australia. 
Lam, P.-M., Lau, K.-T., Ling, H.-Y., Su, Z., \& Tam, H.-Y. (2009). Acousto-ultrasonic sensing for delaminated gfrp composites using an embedded fbg sensor. Optics and lasers in engineering, 47(10), 1049-1055.

Lin, J. (2001). Feature extraction of machine sound using wavelet and its application in fault diagnosis. NDT \& E International, 34(1), 25-30.

Mal, A., Ricci, F., Banerjee, S., \& Shih, F. (2005). A conceptual structural health monitoring system based on vibration and wave propagation. Structural Health Monitoring, 4(3), 283-293.

Muravin, B., Muravin, G., \& Lezvinsky, L. (2010). The fundamentals of structural health monitoring by the acoustic emission method. Paper presented at the Proceedings of the 20th International Acoustic Emission Symposium, November.

Orifici, A., Herszberg, I., \& Thomson, R. (2008). Review of methodologies for composite material modelling incorporating failure. Composite Structures, 86(1), 194-210.

Popovics, J. S. (2009). Recent developments in ndt and shm in the united states. NonDestructive Testing in Civil Engineering, NDTCE, 9.

Shan, C. W., Ghazali, M. I., \& Idris, M. I. (2013). Improved vibration characteristic of flexible polyurethane foam via composite formation. International Journal of Automotive and Mechanical Engineering, 7, 1032-1042.

Simonovski, I., \& Boltežar, M. (2003). The norms and variances of the gabor, morlet and general harmonic wavelet functions. Journal of Sound and Vibration, 264(3), 545-557.

Umar, A. H., Zainudin, E. S., \& Sapuan, S. M. (2012). Effect of accelerated weathering on tensile properties of kenaf reinforced high-density polyethylene composites. Journal of Mechanical Engineering and Sciences, 2, 198-205.

Zohari, M. H., Epaarachchi, J. A., \& Lau, K. (2013). Modal acoustic emission investigation for progressive failure monitoring in thin composite plates under tensile test. Key Engineering Materials, 558, 65-75. 